\title{
Investigation of The Continuity of Training and Mental Health of Athletes During Social Isolation In The Covid-19 Outbreak
}

\author{
Pınar Kaya CIDDI ${ }^{1}$ iD and Elif Aleyna YAZGAN ${ }^{2}$ iD \\ ${ }^{1}$ Istanbul Medipol University, Faculty of Health Sciences, Department of Physiotherapy and Rehabilitation, İstanbul / Turkey \\ ${ }^{2}$ Istanbul Medipol University, Institute of Health Sciences, Physiotherapy and Rehabilitation Department, İstanbul / Turkey
}

*Corresponding author: pkaya@medipol.edu.tr

\begin{abstract}
Purpose: Social distance and isolation measures have been taken to minimize the spread rate of COVID-19 and within these measures, all sports leaques and toumaments have been suspended or canceled. In this study, it is aimed to investigate the training continuity and mental health of athletes during the COVID-19 isolation process and to determine whether they are physically and mentally ready for the next season competition. Methods: 89 athletes, 17.7 \pm 2.72 years old, belonging to different sports branches were included in the study. The training time and mental health of athletes before and after isolation were questioned through the online questionnaire platform. Generalized Anxiety Disorder-7 (GAD-7) and Epidemiologycal Research Center Depression Scale (CES-D) were applied to assess the mental status. Participants were asked questions about their thoughts on sports performances and grouped according to their answers and their anxiety and depression levels were compared. Results: It was observed that most of the athletes had a decrease in the training time compared to before isolation. CES-D scores of athletes who thought that their sports performance decreased during the isolation process and were not ready to return to the matches were higher than athletes who did not think $(\mathrm{p}<0.01)$. GAD-7 and CES-D scores of athletes who were worried about the competitions were higher than other athletes $((\mathrm{p}<0.01)$. Conclusion: The results showed that athletes needed physical and psychological support by sports professionals, both during the isolation process and before returning to sports competitions.
\end{abstract}

Keywords

Athletes, COVID-19, Mental Health, Social İsolation, Training

\section{INTRODUCTION}

COVID-19 is one of the major pathogens targeting the human respiratory system, and the most common symptoms of its infection are fever, cough, chest tightness and shortness of breath (Bogoch et al., 2020, Wang et al., 2020). Due to the lack of preventive and therapeutic medical interventions for its treatment, it has a rapid transmission rate and the number of infected is rapidly increasing (Crisafulli \& Pagliaro, 2020).
Social distancing and isolation measures are taken to minimize the rate of COVID-19's spread. Being isolated at home to prevent social interaction and the spread of the disease is among these measures (Paçenha et al., 2020 ). One of the other measures taken is to suspend or cancel all sports leagues and tournaments between midMarch 2020 and early June 2020 (Escher, 2020). All teams anticipated that their athletes 'health could be negatively affected and stated that the protection of their athletes' health is a priority issue 
and that their athletes should stay at home as part of compulsory home isolation by following government rules (Jukic et al., 2020).

While sports competitions continue, athletes can maintain their physical fitness and sports performance in the best way, but it is thought that the lack of sports competitions and training during the isolation process will create many problems for teams and athletes (Pillay et al., 2019). During isolation, not only the physical performance of the athletes, but also their mental health is negatively affected due to the lack of competition (Hughes et al., 2019, Sarto et al., 2020). Mental health is inseparable from physical health, and problems in mental health increase the risk of physical injury and delay recovery (Reardon et al., 2019). In the light of this information, our study aimed to investigate the continuity of exercise and psychosocial influence of athletes in our country during the isolation period when there were global pandemic and public health restrictions. In this study, it is aimed to investigate the training continuity and mental health of athletes during the COVID-19 isolation process, to determine whether they are physically and mentally ready for the next season competitions, and to make a preliminary assessment to prepare the necessary support programs.

\section{MATERIALS AND METHODS}

\section{Participants}

In order to be able to participate in the study, the participants had to be doing individual or team sports licensed and their sports competitions had to be canceled or suspended. Participants were included in the study via online survey software (Google Surveys) and social media communication (WhatsApp). As a result of the literature review, the total sample size was found to be $n=89$ using the G-Power program with 0.30 effect size, $95 \%$ power and 0.05 margin of error based on the percentage measurement values for the methods to be studied. 160 participants started the online survey, 71 responses were missing and were therefore excluded from the data set. The sample of 89 athletes obtained was included in the study. The study was evaluated by the Istanbul Medipol University Non-Invasive Research Ethics Committee and was approved with the number
10840098-604.01.01-E.15843 (Decision number: 452).

\section{Measurements}

The athletes answered questions using online survey software (Google surveys) in the period corresponding to the beginning of May 2020 during the strictest public health restrictions in Istanbul (After March 10, the date when the coronavirus detected the first cases in Turkey, solid public health restrictions began on March 27). The questionnaire consisted of three parts, where demographic information was obtained, the level of depression was evaluated, and the anxiety level was evaluated.

Demographic characteristics included information on age, gender, body mass index (BMI), presence of chronic disease, and sports branch. In this section, the types and frequencies of training performed before and during isolation were asked. In addition, it was questioned whether he received support for his training program during the isolation process, from whom and in what way he received support, whether he experienced any problems or pain while training, and if so, from whom he received help.

Participants were asked whether their sports performance decreased, whether they felt ready for competitions, whether they would need a psychological support program before returning to competitions, and whether they were concerned about a decrease in their sports performance after recovery in case of COVID-19 infection. While answering these questions, they were asked to mark one of the 'yes / no' options.

Depression levels of the participants were evaluated with the Center for Epidemiologic Studies Depression Scale (CES-D). CES-D is a scale developed by the American National Institute of Mental Health (ANIMH) to determine the level of depression and has validity and reliability in Turkish. The scale consists of 20 questions that measure the emotional state, perceptions and behaviors of the person and are in the form of a self-report. The questions in the scale with a total of 0-60 points are coded in the 4-point likert type and 0-3 points range (Tatar \& Saltukoglu, 2010).

Anxiety levels of the participants were evaluated with the The Generalized Anxiety Disorder-7 (GAD-7). GAD-7 scale is a short selfreport test that evaluates generalized anxiety disorder. It is a 7 -item four-point likert $(0=$ none, $1=$ many days, $2=$ more than half of the days, $3=$ 
almost every day) type scale that evaluates the experiences in the last 2 weeks regarding the questions asked in the scale items. The total scores obtained from the scale are 5, 10, and 15 cut-off points for mild, moderate, and severe anxiety, respectively. It is necessary to investigate and confirm the GAD-7 diagnosis with other methods for patients with a total score of 10 or more (Kroenke et al., 2007). The Turkish validity and reliability of GAD-7 has been made and it has high validity, reliability and good psychometric properties in the clinical sample, similar to the original form (Konkan et al., 2013).

\section{Statistical Analysis}

SPSS 22.00 program was used for statistical analysis. While evaluating the study data, in addition to descriptive statistical methods

\section{RESULTS}

89 participants with a mean age of $17.7 \pm 2.72$ years were included in the study. The sports branches of the participants are shown in Table 1. The sports branches of the participants were as follows: $29.2 \%(n=26)$ basketball, $25.8 \% \quad(n=23)$
(Average, Standard Deviation, Median, Frequency, Ratio, Minimum, Maximum), the normality distribution of the data was evaluated using the Shapiro-Wilk Test. In study, the levels of anxiety and depression among individuals who think and do not think that their sports performance is reduced, who feel ready and do not feel ready for competitions, who need and do not need a psychological support program before returning to competitions, and who are worried about a decrease in sports performance after recovery in the possibility of experiencing COVID-19 infection, and who do not worry will be compared. For comparisons between groups, Mann-Whitney U Test was used for data that did not show normal distribution. Significance was evaluated at $\mathrm{p}$ $<0.001$ and $\mathrm{p}<0.05$ levels.

volleyball, $7.9 \%(\mathrm{n}=12)$ football, $7.9 \%(\mathrm{n}=7)$ taekwondo, $23.6 \%(\mathrm{n}=21)$ rowing (Table 1$)$. None of the individuals had a diagnosis of chronic disease.

Table 1. Demographic Characteristics of Players

\begin{tabular}{|c|c|c|c|}
\hline & $\mathbf{x}$ & sd \\
\hline \multicolumn{2}{|c|}{ Age (years) } & 17.75 & 2.72 \\
\hline \multicolumn{2}{|c|}{ Height (cm) } & 179.88 & 11.9 \\
\hline \multicolumn{2}{|c|}{ Body weight (kg) } & 71.22 & 14.96 \\
\hline \multirow{2}{*}{\multicolumn{2}{|c|}{ BMI $\left(\mathrm{kg} / \mathrm{m}^{2}\right)$}} & 22.31 & 5.32 \\
\hline & & $\mathbf{n}$ & $(\%)$ \\
\hline \multirow{2}{*}{ Gender } & Female & 41 & 46.06 \\
\hline & Male & 48 & 53.93 \\
\hline \multirow{5}{*}{$\begin{array}{l}\text { Sport } \\
\text { Branch }\end{array}$} & Basketball & 26 & 29.2 \\
\hline & Volleyball & 23 & 25.8 \\
\hline & Football & 12 & 7.9 \\
\hline & Taekwondo & 7 & 23.6 \\
\hline & Rowing & 21 & 11.2 \\
\hline
\end{tabular}

BMI: Body Mass Index, $\mathrm{x}$ : Mean, sd: Standard Deviation 
Table 2. Demonstration the Training Status Before and After İsolation

\begin{tabular}{|c|c|c|c|}
\hline Questions & Answers & $\mathbf{n}$ & $(\%)$ \\
\hline \multirow{5}{*}{ How many hours a day did you train before isolation? } & 1 hour/day & 10 & 11.2 \\
\hline & 2 hour/day & 51 & 57.3 \\
\hline & 3 hour/day & 22 & 24.7 \\
\hline & 4 hour/day & 5 & 5.6 \\
\hline & 5 hour/day & 1 & 1.1 \\
\hline \multirow{4}{*}{$\begin{array}{l}\text { How many hours do you train per day during the isolation } \\
\text { process? }\end{array}$} & 1 hour/day & 50 & 56.1 \\
\hline & 2 hour/day & 29 & 32.5 \\
\hline & 3 hour/day & 9 & 10.1 \\
\hline & 4 hour/day & 1 & 1.1 \\
\hline \multirow{2}{*}{$\begin{array}{l}\text { Did you prepare your training program yourself during the } \\
\text { isolation process or did you get help? }\end{array}$} & I prepared it myself. & 49 & 55.05 \\
\hline & I got help. & 40 & 44.9 \\
\hline \multirow{4}{*}{ From whom did you get help for the training program? } & Trainer & 28 & 70 \\
\hline & Conditioner & 5 & 12.5 \\
\hline & Physiotherapist & 3 & 7.5 \\
\hline & Team mate & 4 & 10 \\
\hline \multirow[t]{3}{*}{ In what way did you get help? } & $\begin{array}{l}\text { Whatsapp, zoom, } \\
\text { skype etc. tools }\end{array}$ & 7 & 17.5 \\
\hline & Phone call & 31 & 77.5 \\
\hline & Face to face & 2 & 5 \\
\hline \multirow{2}{*}{$\begin{array}{l}\text { Have you experienced any injuries during training during the } \\
\text { isolation process? }\end{array}$} & Yes & 23 & 25.8 \\
\hline & No & 66 & 74.2 \\
\hline \multirow[t]{3}{*}{ Who did you get help from when you were injured? } & Physiotherapist & 14 & 60.8 \\
\hline & Doctor & 2 & 8.6 \\
\hline & Did not got help & 7 & 31.8 \\
\hline
\end{tabular}

Participants stated that their training frequency before isolation was as follows: $57.3 \%$ $(\mathrm{n}=51) 2$ hours a day, $24.7 \%(\mathrm{n}=22) 3$ hours a day, $11.2 \%(n=10) 1$ hour a day, 5.6\% $(n=5) 4$ hours a day, $1.1 \% \quad(n=1) 5$ hours a day. During the isolation process, the participants stated that their training frequency was as follows: $56.1 \%(n=50) 1$ hour a day, $32.5 \%(\mathrm{n}=29) 2$ hours a day, $10.1 \%$ $(n=9) 3$ hours a day and $1.1 \%(n=1) 4$ hours a day (Table 2). 
While $44.9 \% \quad(n=40)$ of the participants stated that they got help from a professional for the training program during the isolation process, $55.05 \%(n=4)$ stated that they did not get help. Of the participants who got help for the training program, 70\% $(\mathrm{n}=28)$ stated that they got help from their trainers, $12.5 \% \quad(\mathrm{n}=5)$ from a conditioner, $7.5 \%(\mathrm{n}=3)$ from a physiotherapist, while the remaining $10 \%(n=4)$ stated that they received help from their team mates. When asked about the way they got help, $75.6 \%(n=31)$ were using tools such as Whatsapp, zoom, skype, $17.5 \%$ $(\mathrm{n}=7)$ by phone call, and $5 \%(\mathrm{n}=2)$ stated that they communicated face to face (Table 2).

While $25.8 \% \quad(n=23)$ of the participants stated that they experienced injury while training during the isolation process, $74.2 \%(n=66)$ stated that they did not experience any injuries. While $60.8 \%(n=14)$ of those who experienced injuries stated that they got help from a physiotherapist for their injuries during training during the isolation process, $8.6 \%(\mathrm{n}=2)$ stated that they got help from a doctor, $31.8 \%(n=7)$ reported that they did not get help (Table 2).

Table 3. Demonstration of Thinking of A Decrease in Sports Performance, Needing A Pre-Competition Psychological Support Program, Worry About A Decrease in Sports Performance in Case Of COVID-19 İnection and Feeling Ready to Return to Competition

\begin{tabular}{|c|c|c|c|c|c|}
\hline \multirow{2}{*}{ Questions } & & \multicolumn{2}{|c|}{ Yes } & \multicolumn{2}{|c|}{ No } \\
\hline & & $\mathbf{n}$ & $(\%)$ & $\mathbf{n}$ & $(\%)$ \\
\hline \multicolumn{2}{|c|}{$\begin{array}{l}\text { Do you think your sports performance decreased during the } \\
\text { isolation process? }\end{array}$} & 65 & 73 & 24 & 27 \\
\hline \multicolumn{2}{|c|}{$\begin{array}{l}\text { Do you think you need a psychological support program before } \\
\text { returning to sports competitions? }\end{array}$} & 31 & 34.8 & 58 & 65.2 \\
\hline \multicolumn{2}{|c|}{$\begin{array}{l}\text { Are you worried about a decrease in your sports performance in } \\
\text { the event of having a COVID-19 infection? }\end{array}$} & 47 & 52.8 & 42 & 47.2 \\
\hline \multicolumn{2}{|c|}{ Do you feel ready to go back to sports competitions? } & 25 & 28.1 & 64 & 71.9 \\
\hline & & & & $\mathbf{n}$ & $(\%)$ \\
\hline \multirow[t]{4}{*}{$\begin{array}{l}\text { If your answer is no, what is the } \\
\text { reason? }\end{array}$} & \multicolumn{3}{|c|}{$\begin{array}{l}\text { The thought that there may be a decrease in } \\
\text { muscle strength }\end{array}$} & 28 & 43.7 \\
\hline & \multicolumn{3}{|c|}{$\begin{array}{l}\text { The thought that there may be a decrease in } \\
\text { sports-specific skills }\end{array}$} & 8 & 12.5 \\
\hline & \multicolumn{3}{|l|}{ Lack of Motivation } & 19 & 29.6 \\
\hline & \multicolumn{3}{|l|}{ Lack of self-confidence } & 9 & 14 \\
\hline
\end{tabular}

When the athletes were asked whether they felt a decrease in their sports performance according to their individual opinions, $73 \%(\mathrm{n}=65)$ thought that their sports performance decreased, while $27 \%(n=24)$ thought that they did not (Table 3).

When we asked the participants whether they felt ready to participate in sports competitions,
$28.1 \%(\mathrm{n}=25)$ stated that they felt ready, $71.9 \%$ $(n=64)$ stated that they did not feel ready; when the participants were asked about the reasons for not feeling ready for the competition, the reasons were given as follows: $43.7 \% \quad(n=28)$ decreased strength, $29.6 \% \quad(\mathrm{n}=19)$ lack of motivation, $14 \%$ $(n=9)$ lack of self-confidence and $12.5 \%(n=8)$ decreased sports-specific skills (Table 3). 
Table 4. Comparison of Scales According to Thinking of A Decline in Sports Performance and Feeling Ready to Return to Sport Competitions

\begin{tabular}{|c|c|c|c|c|c|}
\hline Scales & Groups & $\mathbf{n}$ & $X$ & SD & $\mathbf{p}$ \\
\hline \multirow{2}{*}{ CES-D } & who thinks their sports performance is decreased & 65 & 22.06 & 11.3 & \multirow{2}{*}{ 0.009: } \\
\hline & $\begin{array}{l}\text { who do not think their sports performance is } \\
\text { decreased }\end{array}$ & 24 & 14.75 & 8.58 & \\
\hline \multirow{2}{*}{ YAB-7 } & who thinks their sports performance is decreased & 65 & 6.94 & 5.01 & \multirow{2}{*}{0.704} \\
\hline & $\begin{array}{l}\text { who do not think their sports performance is } \\
\text { decreased }\end{array}$ & 24 & 6.21 & 4.08 & \\
\hline \multirow{2}{*}{ CES-D } & not feeling ready to return to the competitions & 64 & 22.08 & 10.76 & \multirow{2}{*}{ 0.008* } \\
\hline & feeling ready to return to competitions & 25 & 15 & 10.43 & \\
\hline \multirow{2}{*}{ YAB-7 } & not feeling ready to return to the competitions & 64 & 6.83 & 4.8 & \multirow{2}{*}{0.766} \\
\hline & feeling ready to return to competitions & 25 & 6.52 & 4.76 & \\
\hline
\end{tabular}

When CES-D scores were compared between those who think that their performance have decreased and those who think that they have not, the scores of individuals who think that they have decreased are found to be high and statistically significant $(\mathrm{p}=0.009 ; \mathrm{p}<0.01)$, there was no difference between individuals in the GAD-7 score ( $>0.05$ ), (Table 4).

The CES-D score of the individuals who think they are not ready was found to be higher and statistically significant compared to the individuals who think they are ready $(\mathrm{p}=0.008$; $\mathrm{p}<0.01)$, there was no difference between individuals in the GAD-7 score $(\mathrm{p}>0.05)$, (Table 4).

When participants were asked if they were worried about a decrease in their sports performance in case of a COVID-19 infection, $52.8 \%(n=47)$ said they were worried about a decrease in their performance if they had COVID-
19 infection, while $47.2 \%(n=42))$ stated that they were not concerned (Table 3); The CES-D and GAD-7 scores of the individuals who were concerned were higher and statistically significant compared to the individuals who were not concerned ( $\mathrm{p}=0.001 ; \mathrm{p}<0.01)$, (Table 5).

When the individuals were asked whether they needed a psychological support program before returning to the competition, $34.8 \%(n=31)$ stated that they needed psychological support before returning to the competition, $65.2 \%(n=58)$ said they did not (Table 3). The CES-D and GAD7 scale scores of the individuals who said they needed a psychological support program before returning to the competition were found to be higher and statistically significant compared to the individuals who said they did not need support $(\mathrm{p}=0.001, \mathrm{p}<0.01)$, (Table 5). 
Table 5. Comparison of the Scales According to the Worrying of Having A Decrease in Sports Performance in Case of COVID-19 İnfection and the Need for Pre-Competition Psychological Support Program

\begin{tabular}{|c|c|c|c|c|c|}
\hline Scales & Groups & $\mathbf{n}$ & $X$ & SD & $\mathbf{p}$ \\
\hline \multirow[b]{2}{*}{ CES-D } & $\begin{array}{l}\text { worried about a decrease in their sports } \\
\text { performance in case of COVID- } 19 \text { infection }\end{array}$ & 47 & 23.72 & 10.93 & $0.001 *$ \\
\hline & $\begin{array}{l}\text { not worried about a decrease in their sports } \\
\text { performance in case of COVID- } 19 \text { infection }\end{array}$ & 42 & 16.02 & 9.87 & \\
\hline \multirow[b]{2}{*}{ YAB-7 } & $\begin{array}{l}\text { worried about a decrease in their sports } \\
\text { performance in case of COVID-19 infection }\end{array}$ & 47 & 8.47 & 5.09 & $0.001 *$ \\
\hline & $\begin{array}{l}\text { not worried about a decrease in their sports } \\
\text { performance in case of COVID-19 infection }\end{array}$ & 42 & 4.81 & 3.51 & \\
\hline \multirow{2}{*}{ CES-D } & need pre-competition psychological support & 31 & 28.06 & 9.91 & $0.001 *$ \\
\hline & $\begin{array}{l}\text { not need pre-competition psychological } \\
\text { support }\end{array}$ & 58 & 15.83 & 9.2 & \\
\hline \multirow{2}{*}{ YAB-7 } & need pre-competition psychological support & 31 & 9.39 & 4.36 & $0.001 *$ \\
\hline & $\begin{array}{l}\text { not need pre-competition psychological } \\
\text { support }\end{array}$ & 58 & 5.33 & 4.38 & \\
\hline
\end{tabular}

CES-D: Generalized Anxiety Disorder-7, YAB-7: Center for Epidemiologic Studies Depression, x: Mean, sd: Standard Deviation, Statistically significant difference $(\mathrm{p}<0.05)$

\section{DISCUSSION AND CONCLUSION}

In our study, it was determined that the vast majority of athletes thought that their performance decreased during the isolation process, they were not ready enough to return to sports competitions, and they were also worried about a decrease in their sports performance within the possibility of having COVID-19 infection, and it was observed that they were negatively affected in terms of mental health in this process. In our study, it was observed that most of the athletes had a decrease in their training time compared to before isolation. It was thought that the inability of athletes to do sports-specific training due to the lack of suitable areas for training during the pandemic and staying at home, shortened their training time. When the reasons why the athletes were not ready to return to the sports competitions were investigated, it was seen that they experienced a decrease in their motivation and self-confidence, together with a possible decrease in muscle strength and sportsspecific skills as a result of not doing enough training. All these negative effects show that athletes, who have to spend their time at home for a long time during the global pandemic processes, may need physical and mental support programs before starting the sports competitions. In addition, providing athlete-specific support programs online to prevent loss of athletes' performance in global pandemic processes can reduce the harmful effects of quarantine processes. 
'De-training' results in the total or partial loss of training-induced gains from previous training (Mujika and Padilla, 2001). It is dangerous for athletic performance if stopping the workout or significantly reducing its intensity causes a partial or complete loss of previously improved performance (Hawley and Burke., 1998). For example, it has been reported that senior male kayakers have deteriorated neuromuscular performance after 5 weeks of reduced intensity training and after complete cessation of training (García-Pallarés et al., 2010) Another study concluded that regardless of the intensity of previous endurance and resistance training, only 24 weeks of training interruptions can result in a significant performance loss (Muñoz-Martínez et al., 2017). Decreases in maximum and submaximal exercise performance occur within weeks after cessation of training, and these losses in aerobic performance reduce cardiovascular function and the metabolic potential of muscles (Neufer et al., 1987, Izquierdo et al., 2007). In addition, it has been reported that not doing flexibility exercises for 8 weeks in athletes causes a decrease in flexibility (Caldwell et al., 2009). Reduced or complete absence of strength training has also been shown to cause a loss of muscle mass in athletes (Neufer et al., 1987). After a period of inactivity of 8 to 12 weeks, the strength and performance of team sports athletes decreased by 7\% - 12\% (Mallinson and Murto, 2013).

In our study, it was observed that the individuals had a decrease in training hours during the isolation process compared to the pre-isolation period, and they had a "de-training period". It was thought that this situation might cause individuals to decrease their motivation and think that their performance decreased. It was thought that a detailed and branch-specific exercise prescription was needed in order to minimize the negative effects of the athletes from negative consequences such as a decrease in muscle mass and cardiovascular functions after "de-training" during the isolation process. In addition, it was thought that sports managers should give sufficient time to the athletes before starting the sports competitions, to allow adaptation before restarting the sports competition, and to implement a gradual loading program aimed at reducing the risk of injury.

While training athletes at home during isolation, the intensity and volume of the exercises will be a matter of concern. It may be difficult to monitor and ensure that the weights used by athletes during home training are appropriate and sufficient to keep physical fitness and performance at the required level. While it is possible for normal people to maintain physical fitness with a simple exercise program at home, this is not possible for senior athletes (Koundourakis et al., 2014).

Unsupervised training can expose athletes to injury if done with poor technique and posture (Izquierdo et al., 2007). In our study, it was observed that some of the individuals suffered injuries and received help from their physiotherapists during the training during the isolation process. In addition, almost half of the athletes reported that they received help from their trainers through online communication while planning their training, while other athletes were observed to plan their training by themselves and did not get help. Especially considering the risk of injury and the need for supervision, it was thought that there was a need to encourage and make widespread communication between sports professionals such as trainers and physiotherapists and athletes through online platforms. In isolation processes, the importance of organizing appropriate guidance and support given to athletes by sports professionals (physiotherapist, sports coach, strength and conditioning coach, nutritionist, doctor, psychologist) using technology (video call, e-mail, phone, text messages) is emphasized (Aicale et al., 2018). In this sense, it was thought that there was a need for researches on which ways to reach athletes remotely from their homes are more effective, which teleassessment methods can effectively evaluate the athlete, and the development of platforms that can provide a multidisciplinary accessibility.

Prolonged inactivity, staying away from the team environment, lack of competitions, less qualified interactions with coaches and lack of social support (e.g. fans, sports organizations, media, etc.) negatively affected the athletes psychologically (Jukic et al., 2020). Sports psychologists report a higher demand for online psychological counseling and diagnosis of psychological disorders in the athlete population during the pandemic. 
Among the reasons for applying; Fear of being infected, anxiety not fully recovering physically if infected, lack of access to fitness centers, poor quality sleep, eating disorders, obsessive-compulsive disorder, and family conflicts (Mehrsafar et al., 2020). Inability to manage stress and lack of coping may cause some to experience short or long term depression (Mehrsafar et al., 2020). The athlete participants included in our study stated that they feared infection, thought their sports performance decreased and they were not ready to return to sports competitions, and it was determined that these individuals were negatively affected in terms of mental health and had high levels of anxiety and depression. The results suggested that athletes needed psychological diagnosis and treatment counseling by sports psychologists, both online during the isolation process and before the sports competition.

COVID-19 is thought to have physical and psychological consequences that can affect the safe return of athletes to sports and their general health, and these consequences will adversely affect the future of athletes and the sports sector and may increase the workload on health systems (Frank et al., 2020). Since most of the individuals participating in the study were athletes engaged in team sports, it was thought that there is a need for further studies comparing the level of influence of athletes who do individual and team sports from this process. Considering that these and similar processes can be repeated, it is thought that developing telerehabilitation systems for athletes may be beneficial. As a result, it is thought that the government and teams should support athletes in order to prevent the risks that may occur, and prepare guidelines to ensure a safe return to sports and these guidelines should be implemented as soon as possible.

\section{REFERENCES}

Aicale, R., Tarantino, D., \& Maffulli, N. (2018). Overuse injuries in sport: a comprehensive overview. Journal of orthopaedic surgery and research, 13(1), 309.

Bogoch, I. I., Watts, A., Thomas-Bachli, A., Huber, C., Kraemer, M. U. G., \& Khan, K. (2020). Pneumonia of unknown aetiology in Wuhan, China: potential for international spread via commercial air travel. Journal of Travel Medicine, 27(2), taaa008.
Caldwell, B. P., \& Peters, D. M. (2009). Seasonal variation in physiological fitness of a semiprofessional soccer team. Journal of strength and conditioning research, 23(5), 1370-1377.

Crisafulli, A., \& Pagliaro, P. (2020). Physical activity/inactivity and COVID-19. European Journal of Preventive Cardiology, 2047487320927597.

Escher, A. R. (2020). An Ounce of Prevention: Coronavirus (COVID-19) and Mass Gatherings. Cureus, 12(3), e7345.

Frank, A., Fatke, B., Frank, W., Förstl, H., \& Hölzle, P. (2020). Depression, dependence and prices of the COVID-19-Crisis. Brain, Behavior, and Immunity, 87, 99.

García-Pallarés, J., Sánchez-Medina, L., Pérez, C. E., Izquierdo-Gabarren, M., \& Izquierdo, M. (2010). Physiological effects of tapering and detraining in world-class kayakers. Medicine and science in sports and exercise, 42(6), 1209-1214.

Hawley J., \& Burke L. (1998). Peak Performance: Training and Nutritional Strategies for Sport. St Leonards, Australia: Allen \& Unwin.

Hughes, D., Saw, R., Perera, N. K. P., Perera, N.K.P., Mooney, M. and Wallett, A. et al. (2020). The Australian Institute of Sport framework for rebooting sport in a COVID19 environment. Journal of Science and Medicine in Sport, 23(7), 639-663.

Izquierdo, M., Ibañez, J., González-Badillo, J. J., Ratamess, N. A., Kraemer, W. J., Häkkinen, K. et al. (2007). Detraining and tapering effects on hormonal responses and strength performance. Journal of strength and conditioning research, 21(3), 768-775.

Jukic, I., Calleja-González, J., Cos, F., Cuzzolin, F., Olmo, J., Terrados, N. et al. (2020). Strategies and Solutions for Team Sports Athletes in Isolation due to COVID-19. Sports (Basel), 8(4), 56.

Konkan, R., Şenormancı, Ö., Güçlü, O., Aydın, E., \& Sungur, M. Z. (2013). Generalized Anxiety Disorder-7 (GAD-7) Test Turkish adaptation, validity and reliability. Archives of Neuropsychiatry, 50 (1), 53-59.

Koundourakis, N. E., Androulakis, N. E., Malliaraki, N., Tsatsanis, C., Venihaki, M., \& Margioris, A. N. (2014). Discrepancy between exercise performance, body 
composition, and sex steroid response after a six-week detraining period in professional soccer players. PloS one, 9(2), e87803.

Kroenke, K., Spitzer, R. L., Williams, J. B., Monahan, P. O., \& Löwe, B. (2007). Anxiety disorders in primary care: prevalence, impairment, comorbidity, and detection. Annals of internal medicine, 146(5), 317325.

Mallinson, J.E., \& Murto A.J. (2013). Mechanisms responsible for disuse muscle atrophy: Potential role of protein provision and exercise as countermeasures. Nutrition, 29:22-28.

Mehrsafar, A. H., Gazerani, P., Zadeh A. M., Sánchez J. C. J. (2020). Addressing potential impact of COVID-19 pandemic on physical and mental health of elite athletes. Brain, Behavior, and Immunity, 87, 147-148.

Mujika, I., \& Padilla, S. (2001). Muscular characteristics of detraining in humans. Medicine and science in sports and exercise, 33(8), 1297-1303.

Muñoz-Martínez, F. A., Rubio-Arias, J. Á., Ramos-Campo, D. J., \& Alcaraz, P. E. (2017). Effectiveness of Resistance CircuitBased Training for Maximum Oxygen Uptake and Upper-Body One-Repetition Maximum Improvements: A Systematic Review and Meta-Analysis. Sports medicine (Auckland, N.Z.), 47(12), 2553-2568.

Neufer, P. D., Costill, D. L., Fielding, R. A., Flynn, M. G., \& Kirwan, J. P. (1987). Effect of reduced training on muscular strength and endurance in competitive swimmers. Medicine and science in sports and exercise, 19(5), 486-490.

Peçanha, T., Goessler, K. F., Roschel, H., \& Gualano, B. (2020). Social Isolation During the COVID-19 Pandemic Can Increase Physical Inactivity and the Global Burden of Cardiovascular Disease. American Journal of Physiology: Heart and Circulatory Physiology, 318(6), H1441-H1446.

Pillay, L., Janse van Rensburg, D. C. C., Jansen van Rensburg, A., Ramagole, D. A., Holtzhausen, L., Dijkstra, H. P. \& Cronje, T. (2019). Nowhere to hide: The significant impact of coronavirus disease 2019 (COVID-19) measures on elite and semielite South African athletes. Journal of Science and Medicine in Sport, 23(7), 670-
679.

Reardon, C. L., Hainline, B., Aron, C. M., Baron, D., Baum, A. L., Bindra, A. et al. (2019). Mental health in elite athletes: International Olympic Committee consensus statement. British Journal of Sports Medicine, 53(11), 667-699.

Sarto, F., Impellizzeri, F. M., Spörri, J., Porcelli, S., Olmo, J., Requena, B., . . Franchi, M. V. (2020). Impact of Potential Physiological Changes due to COVID-19 Home Confinement on Athlete Health Protection in Elite Sports: a Call for Awareness in Sports Programming. Sports Medicine, 50(8), 14171419.

Tatar, A., \& Saltukoglu, G. (2010). The adaptation of the CES-depression scale into Turkish through the use of confirmatory factor analysis and item response theory and the examination of psychometric characteristics. Bulletin of Clinical Psychopharmacology, 20:3, 213-227.

Wang, Y., Wang, Y., Chen, Y., \& Qin, Q. (2020). Unique epidemiological and clinical features of the emerging 2019 novel coronavirus pneumonia (COVID-19) implicate special control measures. Journal of Medical Virology, 92(6), 568-576

How to cite this article: Ciddi, P.K. and Yazgan, E. (2020). Investigation of The Continuity of Training and Mental Health of Athletes During Social Isolation In The Covid-19 Outbreak. Int J Disabil Sports HealthSci;3(2):111-120. https://doi.org/10.33438/ijdshs.785527 